\title{
CDC Grand Rounds: Public Health Strategies to Prevent Preterm Birth
}

\author{
Carrie K. Shapiro-Mendoza, $\mathrm{PhD}^{1}$; Wanda D. Barfield, MD ${ }^{1}$; Zsakeba Henderson, MD ${ }^{1}$; Arthur James, MD²; Jennifer L. Howse, PhD ${ }^{3}$;
} John Iskander, $\mathrm{MD}^{4}$; Phoebe G. Thorpe, $\mathrm{MD}^{4}$

Preterm birth (delivery before 37 weeks and 0/7 days of gestation) is a leading cause of infant morbidity and mortality in the United States. In 2013, 11.4\% of the nearly 4 million U.S. live births were preterm; however, $36 \%$ of the 8,470 infant deaths were attributed to preterm birth (1). Infants born at earlier gestational ages, especially $<320 / 7$ weeks, have the highest mortality (Figure) and morbidity rates. Morbidity associated with preterm birth includes respiratory distress syndrome, necrotizing enterocolitis, and intraventricular hemorrhage; longerterm consequences include developmental delay and decreased school performance. Risk factors for preterm delivery include social, behavioral, clinical, and biologic characteristics (Box). Despite advances in medical care, racial and ethnic disparities associated with preterm birth persist. Reducing preterm birth, a national public health priority (2), can be accomplished by implementing and monitoring strategies that target modifiable risk factors and populations at highest risk, and by providing improved quality and access to preconception, prenatal, and interconception care through implementation of strategies with potentially high impact.

Most preterm births are spontaneous and can occur with intact membranes ( $40 \%-45 \%$ of preterm births) or after preterm premature rupture of membranes $(25 \%-30 \%$ of preterm births) (3). The etiology of preterm labor is poorly understood; prevailing theories include infectious and inflammatory processes. Intrauterine infection and inflammation might account for up to $40 \%$ of preterm births, but in many instances, the cause might be subclinical and difficult to detect $(3,4)$. Maternal or fetal complications can often result in preterm birth because of medically indicated induction of labor or cesarean delivery (30\%-35\% of preterm births) (3). Growing awareness of the complications of prematurity has prompted careful evaluation of the indications for and timing of delivery (5).

This is another in a series of occasional MMWR reports titled $C D C$ Grand Rounds. These reports are based on grand rounds presentations at CDC on high-profile issues in public health science, practice, and policy. Information about CDC Grand Rounds is available at http://www.cdc.gov/cdcgrandrounds.
For more accurate estimates of the preterm birth rate, CDC's National Center for Health Statistics transitioned from using the date of last normal menstrual period to the obstetric estimate of gestation at delivery, starting with 2014 births and revising data back to 2007 (G).* Based on the historical last normal menstrual period measure, the U.S. preterm birth rate increased $21 \%$, from $10.6 \%$ in 1990 to $12.8 \%$ in 2006 (7). Since 2007, the first year that data using the obstetric estimate of gestation at delivery were available, the overall rate declined, from $10.4 \%$ in 2007 to $9.6 \%$ in 2014 . However, declines have been disproportionate across racial and ethnic groups (G). In 2014, non-Hispanic black (black) women had the highest preterm birth rate $(13.2 \%)$, followed by American Indians or Alaska Natives (AI/AN) (10.2\%), Hispanics (9.4\%), nonHispanic whites (whites) (8.9\%), and Asian/Pacific Islanders (API) (8.5\%). Compared with the preterm birth rate among whites, the rates of preterm birth among blacks and AI/AN were 1.5 and 1.1, respectively (G).

Declines in infant mortality (53\%) since the 1980s have been largely attributed to increasing preterm survival, owing to improvements in neonatal intensive care and treatments for lung immaturity. Infant mortality rates (deaths in children aged $<12$ months per 1,000 live births) declined from 12.6 in 1980 (8) to 5.96 in 2013 (1). ${ }^{\dagger}$ Despite these declines, racial and ethnic disparities persist. In 2013, the infant mortality rate among black infants (11.2) was 2.2 times higher than that among white infants (5.1). Rates of preterm-related infant mortality $\$$ (per 1,000 live births) provide further evidence of racial and ethnic disparities and highlight the importance of reducing preterm births. Black women have the highest rates of preterm-related infant mortality (4.9), followed by AI/AN women (2.0), Hispanic women (1.8), white women (1.6), and API women (1.5) (1).

\footnotetext{
* Obstetric estimate is defined as the best obstetric estimate of the infant's gestation in completed weeks based on the birth attendant's final estimate of gestation. Preferably, the obstetric estimate is based on an early pregnancy ultrasound.

${ }^{\dagger}$ Linked birth and infant death data are a preferred data source for reporting U.S. infant mortality rates by race and ethnicity; 2013 is the most recent data available.

$\$$ Preterm-related deaths are those where the infant was born preterm (before 37 completed weeks of gestation) with the underlying cause of death assigned to one of the following International Classification of Diseases, 10th edition categories: K550, P000, P010, P011, P015, P020, P021, P027, P070-P073, P102, P220-229, P250-279, P280, P281, P360-369, P520-523, or P77.
} 


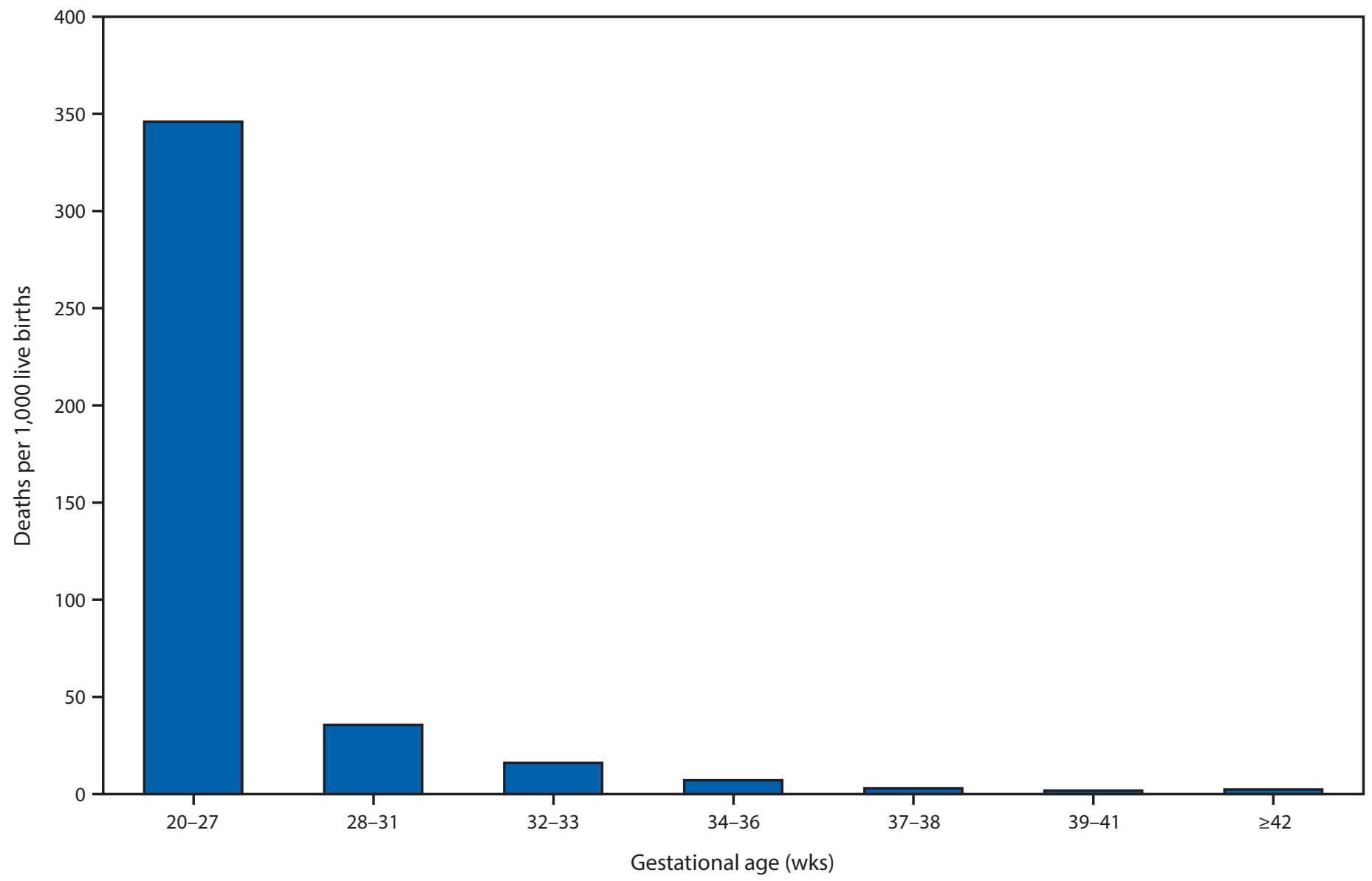

* Deaths in children aged $<12$ months per 1,000 live births.

\section{Strategies to Reduce Preterm Birth and Complications}

Five groups of strategies can reduce the occurrence of preterm births. First, women of childbearing age need access to preconception care services including screening, health promotion, and interventions that will enable them to achieve high levels of wellness, minimize risks, and enter a pregnancy in optimal health. As the prevalence of chronic diseases in women of reproductive age increases, improving health before and between pregnancies is an important strategy to reduce maternal risk factors for preterm birth (9). Chronic conditions, such as diabetes and hypertension, should be well managed and controlled. Modifiable risk factors, including obesity, tobacco use and substance abuse, also should be addressed. Approximately $5.3 \%-7.7 \%$ of U.S. preterm deliveries, and $5.0 \%-7.3 \%$ of U.S. preterm-related deaths are attributable to smoking during pregnancy $(10)$. Increases in tobacco prices, comprehensive smoke-free laws, mass media campaigns, and barrier-free access to quitting assistance are proven populationbased interventions that could reduce cigarette smoking among reproductive-aged women (www.surgeongeneral.gov). Since 2010, state Medicaid programs are required to cover tobaccocessation counseling and drug therapy for pregnant women without cost sharing. In 2012, most obstetricians were unaware of this coverage; however, one third indicated they would offer services if they received Medicaid reimbursement $(11,12)$.

Second, women at risk for preterm delivery need to be identified and offered access to effective treatments to prevent preterm birth. For example, for women who have had a spontaneous preterm delivery, the risk for preterm delivery in subsequent pregnancies is 1.5-2.0 times higher. Among women with a singleton pregnancy and history of spontaneous preterm delivery, 17 alpha-hydroxyprogesterone caproate (17P) can reduce the risk of preterm birth by approximately $30 \%$ (13). Because infants with preterm births from 24 to 34 weeks gestation are at higher risk for respiratory distress syndrome, intraventricular hemorrhage, necrotizing enterocolitis, and perinatal mortality, the American College of Obstetricians and Gynecologists (ACOG) recommends that mothers at risk for preterm delivery should be offered antenatal corticosteroids 
(ANCS) to improve fetal lung maturity (14). A Cochrane review (15) determined that maternal treatment with a single course of ANCS reduced respiratory distress syndrome by $66 \%$, intraventricular hemorrhage by $54 \%$, necrotizing enterocolitis by $46 \%$, and death by $69 \%$, compared with non-ANCS treatment. Further research is needed to determine optimal dosing, timing, and frequency of administration (14).

A third strategy to prevent preterm birth is to discourage nonmedically indicated deliveries, especially before 39 0/7 weeks. Even infants born late preterm (34-36 6/7 weeks) and early term (37-38 6/7 weeks) (5) have higher risks of birth complications (16), infant mortality (Figure) (16), and neurodevelopmental delays (17) than do infants born after 39 completed weeks. Based on these findings, ACOG issued an opinion discouraging nonmedically indicated deliveries (18). Efforts to reduce nonindicated deliveries before 39 weeks have largely succeeded: during 2010-2014, the national average declined from $17 \%$ to $3.4 \% .9$ Approaches to reducing nonmedically indicated deliveries before 39 weeks include clinical leadership, public advocacy (e.g., March of Dimes' [MOD] Healthy Babies are Worth the Wait campaign); quality improvement initiatives (e.g., state Perinatal Quality Collaboratives [PQCs], Collaboration on Innovation and Improvement Network, Centers for Medicare \& Medicaid Services' Strong Start for Mothers and Newborns Initiative); public reporting (e.g., the Joint Commission); and payment reform.

A fourth strategy for reducing preterm birth is preventing unintended pregnancies and achieving optimal birth spacing. Nearly three quarters of teen births are unintended. These pregnancies are at $17 \%$ higher risk for preterm delivery, and teen mothers are more likely to have a second baby within 2 years of the first birth, making preterm delivery more likely for the second birth as well $(19,20)$. Although the U.S. teen birth rate has declined, efforts to reduce teen pregnancy need to continue $(6,20)$, especially in minority communities where teen and preterm birth rates are highest.** Women who become pregnant after age 35 years are also at increased risk for preterm delivery, and they are also more likely to have a chronic medical condition. Regardless of a woman's age, having access to the full range of contraceptive methods is important to prevent unintended pregnancies. Barriers in provider and patient knowledge, availability, and costs should be addressed to ensure the most efficacious contraception method is accessible, including long-acting reversible contraception. ${ }^{\dagger \dagger}$ Providers should be informed about the safety of available contraceptives and reimbursement for contraceptive services $(21,22)$.

\footnotetext{
http://www.leapfroggroup.org/ratings-reports/reports-hospital-performance.

** http://www.cdc.gov/teenpregnancy/.

$\dagger^{\dagger \dagger}$ http://www.cdc.gov/cdcgrandrounds/archives/2013/march2013.htm.
}

BOX. Risk factors for preterm delivery

\author{
Maternal demographic characteristics \\ - Young or advanced maternal age \\ - Black race \\ - Low socioeconomic status \\ Unhealthy lifestyle \\ - Tobacco use \\ - Substance abuse \\ - Low or high prepregnancy body mass index \\ Pregnancy history \\ - Short interpregnancy interval \\ - Previous preterm delivery \\ - Multiple gestations \\ Pregnancy complications \\ - Placental abruption or previa \\ - Polyhydramnios \\ - Oligohydramnios \\ Maternal medical disorders \\ - Thyroid disease \\ - Obesity \\ - Asthma \\ - Diabetes \\ - Hypertension \\ Mental health \\ - Psychological or social stress \\ - Depression \\ Fertility treatments \\ - Assisted reproductive technology (ART) \\ - Non-ART fertility treatments \\ Intrauterine infection
}

Finally, multiple gestations have a higher preterm birth risk. In 2013, it was estimated that assisted reproductive technology contributed to $18.7 \%$ of multiple births, $4.6 \%$ of preterm births, and $5.0 \%$ of very preterm births (23). Electing to transfer a single embryo for pregnancies achieved by assisted reproductive technology can reduce multiple births and the risk for preterm birth (23).

To effectively implement and evaluate these prevention strategies, high-quality surveillance systems are needed to monitor preterm births, associated risk factors, and outcomes. Timely availability of and access to data sources, such as vital records, administrative data, and surveys, are important for monitoring risk factors and outcomes and informing program evaluation at local, state, and national levels. For example, the Pregnancy Risk Assessment Monitoring System (http://www.cdc.gov/prams/) 
collects state-level data on maternal experiences before, during, and shortly after pregnancy, and can measure progress on risk factors, such as prepregnancy and prenatal smoking, and postpartum contraceptive use.

Societal and community factors play an important role in the risk for preterm birth (2). Adverse neighborhood conditions (e.g., residential segregation; concentrated poverty; high crime rates; and lack of goods, services, recreational activities, and access to quality health care), and diminished opportunities (e.g., inferior education and employment; housing market discrimination; and low wages) contribute to the stress of communities and the pregnant women who live in them (2). Although the mechanism is not clear, exposure to acute and chronic stress might affect the maternal neuroendocrine and immune pathways, resulting in increased susceptibility to infection or inflammation and an increased risk for preterm birth (2). Research using multilevel modeling, which links social and population data to clinical and biologic data, could aid in understanding social determinants of health as they relate to preterm birth. Exploring broader social policies to improve the health of mothers, particularly in African American and other communities at high risk, could reduce preterm birth and associated disparities (2).

\section{Ongoing Initiatives to Prevent Preterm Delivery}

Several initiatives are underway to reduce preterm delivery and complications. One is CDC's Maternal and Child Health Epidemiology program. ${ }^{\$ \$}$ This program develops leadership and builds state, local, and tribal level capacity for surveillance, monitoring, and evaluation activities by assigning senior epidemiologists to work with communities. In addition, CDC collaborates with national, state, tribal, and territorial organizations and partners to increase visibility of preterm birth and its consequences, and to help translate science into relevant clinical and public health practice. Ongoing collaborative activities involve ACOG, the American Academy of Pediatrics, MOD, Collaboration on Innovation and Improvement Network, the Association of State and Territorial Health Officials' Healthy Babies Initiative, $\mathbf{9 9}$ and state-based PQCs. ${ }^{* * *}$

Expanding the success of state-based PQCs is another ongoing initiative. The Ohio PQC has advanced evidencebased clinical practices and processes to improve pregnancy outcomes for women and newborns through continuous quality improvement. Interventions underway include the Ohio PQC's Progesterone Project ${ }^{\dagger \dagger}$ and ANCS Project. ${ }^{\text {\$S\$ }}$

\footnotetext{
$\$ \$$ http://www.cdc.gov/reproductivehealth/mchepi/.

99 http://www.astho.org/healthybabies/.

*** http://www.cdc.gov/reproductivehealth/maternalinfanthealth/pqc.htm.

t† https://www.opqc.net/projects/progesterone.

$\$ \$ S$ https://www.opqc.net/projects/OB-ANCS.
}

The Progesterone Project aims to reduce preterm birth rates by $10 \%$ through increased screening, identification, and treatment of pregnant women at risk for preterm birth who could benefit from progesterone treatment. Through quality improvement activities and the use of a toolkit, the ANCS Project aims to increase to $90 \%$ the percentage of women between 24-33 weeks gestation and at risk for preterm delivery who receive any ANCS before delivery.

Finally, MOD is leading a promising initiative to reduce preterm birth. The "Roadmap to 2020 and 2030 Goals" program aims to reduce modifiable risk factors by bundling various interventions through the Healthy Babies are Worth the Wait Community Program.999 Beginning in 2017, the program will reach 16 states with preterm birth rates $>11.5 \%$ with substantial racial/ethnic disparities and approximately 100,000 births per year. In addition, MOD is funding five centers to further research and understand the complex etiology of preterm birth. ${ }^{* * * *}$

During the past decade, considerable advances have been made in medical care for preterm infants, along with corresponding reductions in infant mortality. Continued efforts to reduce preterm birth and its associated racial and ethnic disparities are critical for further reduction of the U.S. infant mortality rate. Through collaborative efforts, public health programs play essential roles in further reducing preterm birth by combining surveillance and evaluation with populationfocused interventions to improve health behaviors, address social determinants, and improve the quality of care for women and infants.

\footnotetext{
999 http://www.marchofdimes.org/professionals/healthy-babies-are-worth-thewait.aspx.

**** http://www.prematurityresearch.org/.
}

\begin{abstract}
${ }^{1}$ Division of Reproductive Health, National Center for Chronic Disease Prevention and Health Promotion, CDC; ${ }^{2}$ Department of Obstetrics and Gynecology, Ohio State University, Columbus; ${ }^{3}$ March of Dimes Foundation, White Plains, New York; ${ }^{4}$ Office of the Associate Director for Science, CDC.

Corresponding author: Carrie K. Shapiro-Mendoza, CShapiroMendoza@cdc.gov, 770-488-6263.
\end{abstract}

\section{References}

1. Matthews TJ, MacDorman MF, Thoma ME. Infant mortality statistics from the 2013 period linked birth/infant death data set. Natl Vital Stat Rep 2015;64:1-30.

2. Behrman RE, Butler AS; Institute of Medicine (US) Committee on Understanding Premature Birth and Assuring Healthy Outcomes. Preterm birth: causes, consequences, and prevention. Washington, DC: National Academies Press (US); 2007.

3. Goldenberg RL, Culhane JF, Iams JD, Romero R. Epidemiology and causes of preterm birth. Lancet 2008;371:75-84. http://dx.doi. org/10.1016/S0140-6736(08)60074-4 
4. Bastek JA, Gómez LM, Elovitz MA. The role of inflammation and infection in preterm birth. Clin Perinatol 2011;38:385-406. http:// dx.doi.org/10.1016/j.clp.2011.06.003

5. Spong CY, Mercer BM, D’Alton M, Kilpatrick S, Blackwell S, Saade G. Timing of indicated late-preterm and early-term birth. Obstet Gynecol 2011;118:323-33. http://dx.doi.org/10.1097/AOG.0b013e3182255999

6. Hamilton BE, Martin JA, Osterman MJK. Births: preliminary data for 2015. National Vital Statistics Reports, Vol. 65, No. 3. Hyattsville, MD: National Center for Health Statistics; 2016. http://www.cdc.gov/nchs/ data/nvsr/nvsr65/nvsr65_03.pdf

7. Martin JA, Osterman MJK, Kirmeyer SE, Gregory ECW. Measuring gestational age in vital statistics data: transitioning to the obstetric estimate. Natl Vital Stat Rep 2015;64:1-20.

8. CDC. Infant mortality and low birth weight among black and white infants-United States, 1980-2000. MMWR Morb Mortal Wkly Rep 2002;51:589-92.

9. Robbins CL, Zapata LB, Farr SL, et al. Core state preconception health indicators - pregnancy risk assessment monitoring system and behavioral risk factor surveillance system, 2009. MMWR Surveill Summ 2014;63(No. SS-3).

10. Dietz PM, England LJ, Shapiro-Mendoza CK, Tong VT, Farr SL, Callaghan WM. Infant morbidity and mortality attributable to prenatal smoking in the U.S. Am J Prev Med 2010;39:45-52. http://dx.doi. org/10.1016/j.amepre.2010.03.009

11. Office of the Surgeon General. The health consequences of smoking - 50 years of progress: a report of the Surgeon General. Rockville, MD: US Department of Health and Human Services, Office of the Surgeon General; 2014. http://www.surgeongeneral.gov/library/reports/50-yearsof-progress/full-report.pdf

12. Tong VT, England LJ, Malarcher A, Mahoney J, Anderson B, Schulkin J. Clinicians' awareness of the Affordable Care Act mandate to provide comprehensive tobacco cessation treatment for pregnant women covered by Medicaid. Prev Med Rep 2015;2:686-8. http://dx.doi.org/10.1016/j. pmedr.2015.08.013

13. Committee on Practice Bulletins-Obstetrics; The American College of Obstetricians and Gynecologists. Practice bulletin no. 130: prediction and prevention of preterm birth. Obstet Gynecol 2012;120:964-73. http://dx.doi.org/10.1097/AOG.0b013e3182723b1b
14. American College of Obstetricians and Gynecologists; Committee on Practice Bulletins-Obstetrics. ACOG practice bulletin no. 127: management of preterm labor. Obstet Gynecol 2012;119:1308-17. http://dx.doi.org/10.1097/AOG.0b013e31825af2f0

15. Brownfoot FC, Gagliardi DI, Bain E, Middleton P, Crowther CA. Different corticosteroids and regimens for accelerating fetal lung maturation for women at risk of preterm birth. Cochrane Database Syst Rev 2013;8:CD006764.

16. Shapiro-Mendoza CK, Lackritz EM. Epidemiology of late and moderate preterm birth. Semin Fetal Neonatal Med 2012;17:120-5. http://dx.doi. org/10.1016/j.siny.2012.01.007

17. Shapiro-Mendoza C, Kotelchuck M, Barfield W, et al. Enrollment in early intervention programs among infants born late preterm, early term, and term. Pediatrics 2013;132:e61-9. http://dx.doi.org/10.1542/ peds.2012-3121

18. American College of Obstetricians and Gynecologists. ACOG committee opinion no. 561: nonmedically indicated early-term deliveries. Obstet Gynecol 2013;121:911-5. http://dx.doi.org/10.1097/01. AOG.0000428649.57622.a7

19. CDC. Vital signs: repeat births among teens_-United States, 2007 2010. MMWR Morb Mortal Wkly Rep 2013;62:249-55.

20. Romero L, Pazol K, Warner L, et al. Vital signs: trends in use of longacting reversible contraception among teens aged 15-19 years seeking contraceptive services-United States, 2005-2013. MMWR Morb Mortal Wkly Rep 2015;64:363-9.

21. Gavin L, Moskosky S, Carter M, et al. Providing quality family planning services: recommendations of CDC and the U.S. Office of Population Affairs. MMWR Recomm Rep 2014;63(No. RR-04).

22. Gee RE, Brindis CD, Diaz A, et al. Recommendations of the IOM clinical preventive services for women committee: implications for obstetricians and gynecologists. Curr Opin Obstet Gynecol 2011;23:471-80. http://dx.doi.org/10.1097/GCO.0b013e32834cdcc6

23. Sunderam S, Kissin DM, Crawford SB, et al. Assisted reproductive technology surveillance-United States, 2013. MMWR Surveill Summ 2015;64(No. SS-11). http://dx.doi.org/10.15585/mmwr.ss6411a1 